\title{
A Study on the Pattern of Bacterial Pathogens Isolated in Neonatal Septicemia
}

\author{
Deepti R. Angadi ${ }^{*}$ and Sreedevi Hanumantha ${ }^{2}$ \\ ${ }^{1}$ Department of Microbiology, PES Institute of Medical Sciences, Kuppam, Chittoor, AP, India \\ ${ }^{2}$ GITAM Institute of Medical Sciences, Visakhapatnam, India \\ *Corresponding author
}

\begin{tabular}{|c|c|}
\hline & A B S T R A C T \\
\hline & The varying microbiological pattern of septicemia in neonates warrants the need for an \\
\hline Keywords & $\begin{array}{l}\text { ongoing review of the causative organisms and their antimicrobial susceptibility pattern. } \\
\text { The incidence of bacteremia in neonates varies widely. As neonatal septicemia is life }\end{array}$ \\
\hline Blood Agar, & threatening condition, delay in diagnosis and treatment may lead to adverse complications, \\
\hline $\begin{array}{l}\text { Septicemia in } \\
\text { Neonates, GPC }\end{array}$ & $\begin{array}{l}\text { hence isolation tollowed by antibiotic sensitivity are crucial for prompt treatment. The } \\
\text { blood-broth media were incubated for } 7 \text { days at } 37^{\circ} \mathrm{C} \text { under aerobic atmosphere. Blind }\end{array}$ \\
\hline Article Info & $\begin{array}{l}\text { subcultures were done on blood agar, chocolate agar and MacConkey agar media after } 24 \\
\text { hours, } 48 \text { hours (when no growth was found upon first subculture) and on } 7 \text { th day(when }\end{array}$ \\
\hline $\begin{array}{l}\text { Accepted: } \\
30 \text { October } 2017 \\
\text { Available Online: } \\
10 \text { December } 2017\end{array}$ & $\begin{array}{l}\text { found sterile upon second subculture) of incubation. The cultures were declared negative } \\
\text { only after } 7^{\text {th }} \text { day of incubation. In our work, of these } 49 \text {, GPCs were isolated from } \\
26(53 \%) \text { blood samples which were predominant cause of septicemia in neonates } \\
\text { compared to GNBs which were isolated from } 21(42.85 \%) \text { cases followed by non } \\
\text { candidaalbicans isolated from } 2(4.08 \%) \text { blood samples. }\end{array}$ \\
\hline
\end{tabular}

\section{Introduction}

Neonatal sepsis can be defined as a clinical entity occurring in the first month of life associated with systemic signs and symptoms confirmed by a positive blood culture. Sepsis has remained a leading cause of morbidity and mortality worldwide in the neonates despite of careful hygiene practices and the use of broad spectrum antibiotics (Naher and Khamael, 2013).

In developing countries, neonatal infections are estimated to cost 1.6 million annual deaths accounting for about $40 \%$ of all neonatal deaths. The incidence of neonatal sepsis according to data from National Neonatal Perinatal Database (NNPD, 2002-03) is 30 per 1000 live births. (National Neonatal
Perinatal Database 2005, 2002-2003). Early diagnosisand aggressive treatment with antibiotics and good supportive care save most cases of neonatal sepsis (Aggarwal et al., 2001). Incidence of neonatal septicemia widely varies from region to region within our country also (Rathod et al., 2012).

Neonatal septicemia clinically can be broadly classified on the basis of onset of symptoms into early onset sepsis (EOS; in first week of life) and late onset sepsis (LOS; after 1 week of life). Risk factors include both maternal and neonatal for the occurrence of septicemia among neonates. Maternal causes include group B streptococcal (GBS) colonization, chorioamniotis, multiple deliveries, prolonged 
rupture of membranes (PROM), urinary tract infection and neonatal factors include preterm birth, low birth weight etc. (Raha et al., 2014)

The clinical features are nonspecific and lead to the difficulty indiagnosis of neonatal septicemia on clinical grounds alone. Patients may present with one or more of the following symptoms and signs.

A) Jaundice

B) Apnoea

C) Respiratory distress

D) Meconium aspiration syndrome

E) Umbilical sepsis, conjunctivitis, abscess, pyoderma as foci of infection

F) Meningitis

G) Pneumonia

H) Urinary tract infection

\section{I) Sclerema}

J) Otherfeatures such as intestinal obstruction, paralytic ileus, hemolytic disease of newborn (Tallur et al., 2000).

Advances in early diagnosis and treatment have led to constant change in the bacteriological profile of neonatal septicemia with the most common etiologic agents being GBS and Coagulase negative Staphylococci (CONS) in developed industrialized countries. However, in the developing countries, these organisms are rare with an entirely different spectrum of bacteria (Kuruvilla et al., 1986).

The gold standard for diagnosis of septicemia is the isolation of bacterial agent from blood culture (Nwadioha et al., 2010).
The varying microbiological pattern of septicemia in neonates warrants the need for an ongoing review of the causative organisms and their antimicrobial susceptibility pattern. The incidence of bacteremia in neonates varies widely (Karki et al., 2010).

As neonatal septicemia is life threatening condition, delay in diagnosis and treatment may lead to adverse complications, hence isolation followed by antibiotic sensitivity are crucial for prompt treatment (Jain et al., 2003).

Increase in resistance has been noted against many antibiotics in the published medical literature. The investigators (Joshi et al., 2010) reported the predominant resistance of their isolates to cephalosporins, piperacillin and gentamicin. In another work by Mane and others (Mane et al., 2010) most of the clinical isolates had high resistance to $3^{\text {rd }}$ generation cephalosporins, but being susceptible to carbapenems and vancomycin.

Most of the organisms have developed multidrug resistance (MDR) over the last two decades due to indiscriminate use of antibiotics and lack of legislation to control their use and have shown high antibiotic resistance in bacterial pathogens of neonatal septicemia, clinical features being nonpathognomonic of causative agent. Isolation of the infecting bacterium from the blood specimen followed by antibiotic susceptibility testing are paramount for the institution of effective antibacterial therapy and hence this helps to improve recovery of neonate from septicemia.

\section{Materials and Methods}

A total of 122 neonates clinically suspected of neonatal septicemia reported to Hospital, were examined during a study period and the criteria were as outlined below. 


\section{Inclusion Criteria}

Clinically suspected cases of neonatal septicemia.

\section{Exclusion Criteria}

Neonates clinically suspected of septicemia but had received antibiotics were excluded from the study.

Patients presented to department of pediatrics (NICU), were examined clinically by pediatricians and 122 cases of neonatal septicemia were identified on the basis of the signs and symptoms and were included for the study. This is followed by collection of blood for culture after obtaining informed expressed written consent.

\section{Blood Specimen Collection}

$1-2 \mathrm{~mL}$ of blood was collected from the peripheral veins following all standard aseptic precautions as per CLSI ${ }^{33}$ guidelines. The collected blood specimen was immediately inoculated onto $5 \mathrm{~mL}$ (when $1 \mathrm{~mL}$ was obtained) or $10 \mathrm{~mL}$ (when $2 \mathrm{~mL}$ was obtained) of liquoid broth (BHI broth with SPS) culture medium and mixed gently immediately.

Processing of sample and approach to identification

The blood-broth media were incubated for 7 days at $37^{\circ} \mathrm{C}$ under aerobic atmosphere. Blind subcultures were done on blood agar, chocolate agar and MacConkey agar media after 24 hours, 48hours (when no growth was found upon first subculture) and on 7th day(when found sterile upon second subculture) of incubation. The cultures were declared negative only after $7^{\text {th }}$ day of incubation. The colony characteristics including results of microscopic morphologic features of the colony such as Gram-staining and hanging drop preparation were noted Finally the bacterial pathogen was identified by subjecting the growth for standard biochemical and other necessary tests. The culture media, chemicals, and oxidase discs for the study were procured from HIMEDIA, Mumbai, India.

\section{Results and Discussion}

Of 122 blood cultures carried out, 49 yielded the growth. In our work, of these 49, GPCs were isolated from 26(53\%) blood samples which were predominant cause of septicemia in neonates compared to GNBs which were isolated from $21(42.85 \%)$ cases followed by non-candida albicans isolated from $2(4.08 \%)$ blood samples.

\section{Includes 6 MRSA}

Among 47 bacterial culture positive blood samples, S.aureus were 14(29.78\%), of which $6(42.8 \%)$ tested MRSA. CONS were from $9(19.14 \%)$ samples, followed by Streptococcus species from $2(4.25 \%)$ and Pneumococcus from 1(2.12\%) sample. $14(29.78 \%)$ blood samples yielded K.aerogenes, followed by isolation of Acinetobacter species in 4(8.51\%), and E.coli, C. freundii and P.aeruginosa, were isolated from $1(2.12 \%)$ blood sample each. 23 cases of EOS showed GPCs followed by GNBs in 20 . But GPCs were detected only in 3 cases of LOS followed by GNB in 1 case. However, statistically the difference was not found significant $(\chi 2=0.13 ; \mathrm{p}>0.05)$.

The present prospective study, bacterial culture positivity from blood samples was noted in $47(38.52 \%)$ among the 122 cases studied. (Tallur et al., 2000) reported $156(64.87 \%)$ blood samples positive for bacterial isolates of total 242 cases studied which is higher than the present study. Whereas, (Kaistha et al., 2009) recorded 
296(13.17\%) blood culture positivity for bacterial isolates among 2247 cases in their retrospective study (Agnihotri et al., 2004). found 588(19.2\%) culture positive cases among 3064 cases studied which is less when compared to our study. The differences in the culture positivity rates noticed in different studies could be attributed to geographical distribution and also type of study- for instance retrospective or prospective and also whether the patients were on antibiotics or not before obtaining blood sample for culture.

Table.1 Distribution of 49 culture positive isolates from blood cultures of 122 neonatal septicemia cases studied

\begin{tabular}{|l|c|}
\hline Broad type of organism & No (\% of cases) \\
\hline GPC & $26(53.0)$ \\
\hline GNB & $21(42.85)$ \\
\hline Non candida albicans & $02(4.08)$ \\
\hline Total & 49 \\
\hline
\end{tabular}

Table.2 Distribution of 47 bacterial isolates (organism wise) obtained

\begin{tabular}{|l|l|}
\hline Organism & No $(\%)$ of isolates \\
\hline S.aureus & $14 *(29.78)$ \\
\hline CONS & $9(19.14)$ \\
\hline Streptococcus species & $2(4.25)$ \\
\hline Pneumococcus & $1(2.12)$ \\
\hline K.aerogenes & $14(29.78)$ \\
\hline Acinetobacter species & $4(8.51)$ \\
\hline E. coli & $1(2.12)$ \\
\hline C. fruendii & $1(2.12)$ \\
\hline P. aeruginosa & $1(2.12)$ \\
\hline Total & 47 \\
\hline
\end{tabular}

Table.3 Distribution of 47 bacterial isolates of neonatal septicaemic cases in association with onset of septicemia

\begin{tabular}{|l|l|l|}
\hline Onset of septicemia & GPC & GNB \\
\hline EOS & 23 & 20 \\
\hline LOS & 3 & 1 \\
\hline Total & 26 & 21 \\
\hline
\end{tabular}

Table.4 Distribution of bacterial culture positivity rates in different studies

\begin{tabular}{|c|c|c|}
\hline Authors and reference & No. of cases studied & No(\%) of culture positive cases \\
\hline Talluret al., ${ }^{6}$ & 242 & $156(64.87)$ \\
\hline Kaisthaet al., ${ }^{13}$ & 2247 & 296(13.17) \\
\hline Agnihotri et al., ${ }^{14}$ & 3064 & $588(19.2)$ \\
\hline Present study & 122 & $47(38.52)$ \\
\hline
\end{tabular}


Table.5 Distribution of the most commonly isolated bacteria (Klebsiella) from blood cultures of clinically suspected neonates in different studies

\begin{tabular}{|c|c|c|}
\hline Authors and reference & Organism & No (\%) of isolates \\
\hline Talluret al., $^{6}$ & $\begin{array}{c}\text { Klebsiella species (K.pneumoniae, } \\
\text { K.aerogenes, K.oxytoca) }\end{array}$ & $84(33.76)$ \\
\hline Kaisthaet al., $^{13}$ & Klebsiella species & $84(28.3)$ \\
\hline Mustafa and Ahmed $^{15}$ & Klebsiella (K.pneumoniae) & $22(35)$ \\
\hline Present study $^{15}$ & Klebsiella(K.aerogenes) & $14(29.78)$ \\
\hline
\end{tabular}

Spectrum of bacterial pathogens observed in causing neonatal septicemia in various studies

In the present work, GPCs $(26 ; 53 \%)$ were principal bacterial agents of neonatal septicemia than GNBs $(21 ; 42.85 \%)$ which closely matches with the observations made by Stoll et al., where in predominant isolations were GPCs accounting for $73 \%$, GNBs being $27 \%$ only. Reports of Grampositive bacteremias, however, are accumulating in the last three decades. (Kuruvilla et al., 1986)

However, (Joshi et al., 2000) and coworkers reported isolation of GNBs more predominantly that was reported in $67.2 \%$ cases in their study. (Kaistha et al., 2009) recorded gram negative septicemia in $80.4 \%$ of neonates.

(Nwadioha et al., 2010) also documented high incidence of gram negative bacteremia seen in $69.3 \%$ of cases and stated that predominance of either GPCs or GNBs is influenced by geographical location and changes taking place on time.

As presented in table 5, in our study, out of 47 bacterial isolates, K.aerogenes was the principal etiological agent seen in $29.78 \%$ neonates that was similar to the reports of those of (Tallur et al., 2000) who also reported Klebsiella species (K.pneumoniae, K.aerogenes, K.oxytoca) as the most common bacterial pathogen that was detected in
84(33.76\%) cases, (Kaistha et al., 2009) who also recorded Klebsiella species in 84(28.3\%), and (Mustafa and Ahmed, 2014) who also noted in their study $35 \% \mathrm{~K}$. pneumoniae isolates as most commonest bacterium.

In the present study, EOS was predominantly seen compared to LOS. Most common organism isolated was $K$. aerogenes.

\section{References}

Aggarwal R, Sarkar N, Deorari AK. Sepsis in newborn. Indian $\mathrm{J}$ of pediatr. 2001; 58: 1143-47.

Agnihotri N. Kaisath N. Gupta V. Antimicrobial susceptibility of isolates from neonatal septicaemia. Jpn J Infect Dis. 2004; 57: 273-75.

Jain NK, Jain VM, Maheshwari S. Clinical profile of neonatal sepsis. Katmandu Univ Med J. 2003; 1: 117-20.

Joshi SG, Ghole VS, Niphadjar KB. Neonatal gram negative bacteremia. Indian $\mathrm{J}$ Pediatr. 2000; 67: 27-32.

Kaistha N, Mehta M, Singla N, Garg R, Chander J. Neonatal septicemia isolates and resistance patterns in a tertiary care hospital of North India. J Infect DevCtries. 2009; 4: 055-057.

Karki S, Rai GK, Manandhar R. Bacteriological analysis and antibiotic sensitivity pattern of blood culture isolates in Kanti children hospital. J Nepal Paediatr Soc. 2010; 30: 94-97.

Kuruvilla KA, Pillai S, Jesudan M, Jena AK. 
Bacteriological profile of sepsis in a neonatal unit in south India. Indian Pediatr. 1986; 23: 595-598

Mane AK, Nagdeo NV, Thombare VR. Study of neonatal septicaemia in a tertiary care hospital in rural Nagpur. Journal of recent advances in applied sciences. 2010; 25: 19-24.

Mustafa $\mathrm{M}$ and Ahmed SL. Bacteriological profile and antibiotic susceptibility patterns in neonatal septicemia in view of emerging drug resistance. $\mathrm{J}$ Med Allied Sci. 2014; 4: 02-08.

Naher HS and Khamael AB. Neonatal sepsis: the bacterial causes and the risk factors. Int Res J Medical Sci. 2013; 1:19-22.

National Neonatal Perinatal Database 2005. Report for the year 2002-2003. National Neonatology Forum, India: 13-19.

Nwadioha SI, Nwokedi EOP, Kashibu E, Odimayo MS, Okwori EE. A review of bacterial isolates in blood cultures of children with suspected septicemia in a Nigerian tertiary hospital. Afr JMicrobiol Res. 2010; 4: 222-225.

Raha BK, Baki MA, Begum T, Nahar N, Jahan N, Begum M. Clinical, Bacteriological Profile \& Outcome of Neonatal Sepsis in a Tertiary Care Hospital. Medicine Today. 2014; 26: 18-29.

Rathod SD, Bhatia PV, Patel PH. Pethani1 JD, Patel LD, Chauhan B. Bacteriological analysis and resistance pattern among various culture isolates from neonatal septicemia at tertiary care hospital of Ahmedabad. Natl J Med Res. 2012; 2: 466-69.

Tallur SS, Kasturi AV, Nadgir SD, Krishna BV. Clinico-bacteriological study of neonatal septicemia in Hubli. Indian $\mathbf{J}$ Pediatr. 2000; 67: 169-174.

\section{How to cite this article:}

Deepti R. Angadi and Sreedevi Hanumantha. 2017. A Study on the Pattern of Bacterial Pathogens Isolated in Neonatal Septicemia. Int.J.Curr.Microbiol.App.Sci. 6(12): 4358-4363. doi: https://doi.org/10.20546/ijcmas.2017.612.500 